\title{
Rubbery Wound Closure Adhesives. II. Initiators for and Initiation of 2-Octyl Cyanoacrylate Polymerization
}

\begin{tabular}{|c|c|}
\hline Journal: & Journal of Polymer Science, Part A \\
\hline Manuscript ID: & Draft \\
\hline Wiley - Manuscript type: & Original Article \\
\hline Keywords: & $\begin{array}{l}\text { networks }<\mathrm{N} \text {, rubber }<\mathrm{R} \text {, adhesives }<\mathrm{A} \text {, polyisobutylene, cyanoacrylate, } \\
\text { initiators }<\mathrm{I}\end{array}$ \\
\hline
\end{tabular}




\title{
Rubbery Wound Closure Adhesives. II. Initiators for and Initiation of 2-Octyl Cyanoacrylate Polymerization
}

\author{
Istvan Szanka ${ }^{1,2}$, Amalia Szanka ${ }^{1,2}$, and Joseph P. Kennedy ${ }^{1}$ \\ ${ }^{1}$ Institute of Polymer Science, The University of Akron, Akron, OH 44325-3909, USA \\ ${ }^{2}$ Polymer Chemistry Group, Institute of Materials and Environmental Chemistry, Research Centre for \\ Natural Sciences, Hungarian Academy of Sciences, H-1117 Budapest, Magyar tudósok krt. 2, Hungary \\ Correspondence to: Joseph P. Kennedy (E-mail: josep19@uakron.edu)
}

\section{ABSTRACT}

The polymerization of 2-octyl cyanoacrylate (OctCA) initiated by five $\mathrm{N}$-bases [N,N-dimethyl- $p$ toluidine (DMT), pyridine (Pyr), triethyl amine $\left(\mathrm{Et}_{3} \mathrm{~N}\right)$, azobicyclo[2.2.2]octane ( $\left.A B C O\right)$, and diazobicylo[2.2.2]octane (DABCO)] was investigated. Our main objective was to assess the suitability and relative reactivity of these initiators for neat OctCA polymerization as wound closure adhesives. Methodologies were developed to determine stir-stop and set times of OctCA polymerization and to use these quantities to assess initiation reactivity. According to these studies $\mathrm{Et}_{3} \mathrm{~N}, \mathrm{ABCO}, \mathrm{DABCO}$, and Pyr are most reactive initiators, while DMT is much less reactive. Polymerizations were much faster in the presence of small amounts of tetrahydrofuran than toluene, indicating solvent polarity effects. Initiator reactivity is discussed in terms of structural parameters. NMR and MALDI-TOF analyses of low molecular weight P(OctCA) prepared with DMT did not show evidence for the expected aromatic head group proposed by earlier investigators, which suggests complex initiation mechanism.

KEYWORDS: network, rubber, adhesives, polyisobutylene, cyanoacrylate, initiators

\section{INTRODUCTION}

Alkyl cyanoacrylates (CAs), typically butyl- or 2octyl cyanoacrylate (Bu-CA, OctCA), are commercially successful wound closure adhesives, marketed under a variety of trade names, such as Hystoacryl ${ }^{\circledR}$, Dermabond ${ }^{\circledR}$, etc. The active ingredient in gold standard contemporary wound closure adhesives is OctCA.

These CAs, due to the strongly electronwithdrawing 2-cyanide and -ester substituents at the vinyl function, are extremely reactive monomers that rapidly polymerize anionically upon contact with a variety of initiators, including even the weakest nucleophiles. ${ }^{1-3}$

The first part of this series of publications concerned the design, synthesis, characterization, structure, and in vitro testing of rubbery homo- and conetworks prepared with $\varnothing(\mathrm{PIB}-\mathrm{CA})_{3}$, and OctCA plus $\varnothing(\mathrm{PIB}-\mathrm{CA})_{3}$, respectively, as potential occlusive wound closure adhesives (see the first paper of this series of publications). We analyzed the advantages/disadvantages of known alkyl-CA skin adhesives, and demonstrated that flexibilizing them by the covalent incorporation of rubbery PIB moieties greatly improves their applicability as potential wound closure adhesives. We continued research in this area and determined the "stir-stop time" and "set time" of select CA polymerization initiators. We define stir-stop time the time the viscosity of a liquid wound closure adhesive increases to the point where stirring stops, and set time the time a liquid wound closure adhesive becomes an essentially tack free skin closure. Set times are 
of great practical significance for health professionals who use liquid wound closure adhesives. Surgeons and nurses prefer set times in the $30-120$ seconds range.

Wound closure adhesives are packaged in special delivery devices in which the cyanoacrylate (plus a variety of additives) is sealed in a thin glass capsule that is crushed upon deployment, forcing the liquid monomer through a small porous sponge (typically polypropylene or nylon) at the delivery port onto the skin. Figure 1 shows such a device.

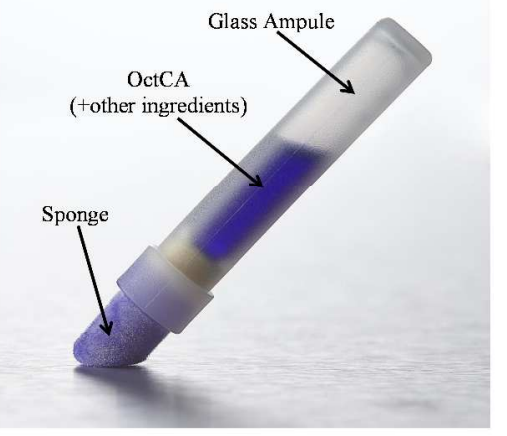

FIGURE 1 A typical delivery device for cyanoacrylate wound closure adhesives. The active ingredients (plus various additives, i.e., stabilizer, viscosifying agent, dye, etc.) are in a thin walled glass ampule, which, when broken, sends the liquid through the sponge onto the skin.

It is not generally known that the sponge at the tip of the device performs two critical functions: (a) it contains an initiator, a key ingredient that induces the polymerization of the CA as it is squeezed through the sponge, and (b) it helps delivering the adhesive evenly over the targeted surface. Absent the initiator, set time is significantly lengthened, which may render the adhesive practically useless. The set time of a commercially acquired Dermabond ${ }^{\circledR}$ sample was $50 \pm 10$ seconds after the glass capsule was shattered and the liquid squeezed through the sponge onto a glass surface. In contrast, the set time increased to 8-10 minutes when the vial was shattered and the liquid spilled directly over the same surface without contacting the sponge. A Dermabond ${ }^{\circledR}$ sample remained liquid for over two weeks after being exposed to humid air in an open vial.

The nature and concentration of initiators used for the polymerization of OctCA in commercial devices are closely guarded secrets and our search of the scientific literature to identify specific initiators remained fruitless. Searching the patent literature gave some clues as to the identity of initiators, and other ingredients (plasticizing agents, stabilizers, thickeners, $\mathrm{pH}$ modifiers, preservatives, dyes, etc.) used in combination with OctCA in commercial formulations.

Herein we describe investigations to gain insight into the mechanism of initiation of $C A$ polymerizations by $\mathrm{Et}_{3} \mathrm{~N}, \mathrm{ABCO}, \mathrm{DABCO}, \mathrm{Pyr}$, and DMT, and to assess their relative polymerization reactivities. Our findings are of interest for controlling the set time of OctCA, and for the homopolymerizations of $\varnothing(\mathrm{PIB}-\mathrm{CA})_{3}$ and copolymerizations of OctCA plus $\varnothing$ (PIB-CA $)_{3}$ to flexible wound closures (see the previous paper in this series). This paper also concerns an assessment of the relative reactivities of the above five bases for OctCA polymerization, efforts to elucidate the mechanism of initiation of OctCA polymerization, and a discussion of the results in terms of structural considerations.

\section{EXPERIMENTAL}

\section{Materials and Procedures}

Azobicyclo[2.2.2]octane (ABCO, Alfa Aesar), diazobicyclo[2.2.2] octane (DABCO, Alfa Aesar), triethyl amine $\left(\mathrm{Et}_{3} \mathrm{~N}\right.$, Aldrich), and pyridine (Pyr, Fischer Chem.) were used as received without further purification. Additional materials, instrumentation, and procedures have been described in the first paper of this series (see the previous paper in this series).

GPC and ${ }^{1} \mathrm{H} \quad$ NMR instrumentation and associated procedures have been described in 
our preceding publication (see the previous paper in this series).

FTIR measurements were carried out with a Shimadzu FTIR-8300 equipped PIKE MIRacle Attenuated Total Reflectance (ATR) accessory with diamond crystal plate. A drop of liquid adhesive was placed on the diamond crystal, and IR measurements were acquired at room temperature. Thirty scans were obtained and averaged with $8 \mathrm{~cm}^{-1}$ resolution.

MALDI-TOF spectra were recorded on a Bruker Reflex II time-of-flight mass spectrometer equipped with a nitrogen laser (Laser Science) operating at $337 \mathrm{~nm}$ and $20 \mathrm{~Hz}$ repetition rate. To facilitate mass analysis, efforts were made to reduce the molecular weight of $\mathrm{P}(\mathrm{OctCA})$ samples. Thus, OctCA polymerizations were carried out at low monomer concentrations (e.g., $[M] /[1]=10)$, however, the $M_{n}$ could not be decreased below $\sim 20,000 \mathrm{~g} / \mathrm{mol}$. The MALDI matrix solution was prepared by dissolving 2[(2E)-3-(4-tert-butylphenyl)-2-methylprop-2enylidene]malononitrile (DCTB) and potassium trifluoroacetate $(100: 10)$ in dry $\mathrm{N}, \mathrm{N}$ dimethylformamide (DMF) $(20 \mathrm{mg} / \mathrm{mL})$. Samples were prepared by depositing $0.5 \mathrm{~mL}$ matrix solution on the stainless steel MALDI target, drying it in a gentle stream of air, placing on top of the dried matrix a layer of $0.5 \mathrm{~mL}$ $\mathrm{P}($ OctCA $)$ solution $(20 \mathrm{mg}$ polymer $/ \mathrm{mL}$ dichloromethane), and drying the system in a gentle stream of air. For the sandwich method a second matrix layer (using $0.5 \mathrm{~mL}$ matrix solution) was deposited on top of the dried polymer layer, producing a matrix-samplematrix sandwich.

\section{Stir-Stop Time}

One way to assess the reactivity of initiators is in terms of stir-stop time, i.e., the time (in seconds) liquid OctCA becomes a non-stirrable mass upon the addition of a well-defined amount (moles) of initiator at room temperature. Thus, experiments were carried out by placing in a $5 \mathrm{~mL}$ flat-bottom screw cap vial $1 \mathrm{~mL}$ OctCA and a Teflon coated small (1 $\mathrm{cm})$ magnetic stir bar. At time $=0$ a known amount of initiator (in certain cases dissolved in toluene or THF) was added to the monomer by a microsyringe, the vial was quickly capped, manually strongly agitated for 1-2 seconds, placed on a stirring plate, and stirred at $\sim 60$ rpm. Stir-stop time (in seconds) was recorded when stirring suddenly stopped (the charge "froze") due to the increased viscosity of the system. (See also the next section for a method to determine monomer conversion at gel time.)

Polymerizations induced by all five initiators were highly exothermic and experiments were carried out to follow heat evolution. In these experiments the reactor vial was hermetically capped with a rubber septum through which a thermocouple was inserted into the charge, and the heat evolved after initiator addition was followed as a function of time. Figure 2 shows the temperature-time profile of a representative experiment. The process starts with a lengthy induction period (may be several hundred seconds), in the course of which the initiator consumes the $\mathrm{SO}_{2}$ stabilizer in the monomer. Subsequently, rapid exothermic polymerization ensues. During the polymerization the viscosity of the charge increases very rapidly until a mass of gooey polymer forms and stirring becomes impossible. The stir-stop time, i.e., the time when stirring stops, is viewed as a measure of initiator reactivity.

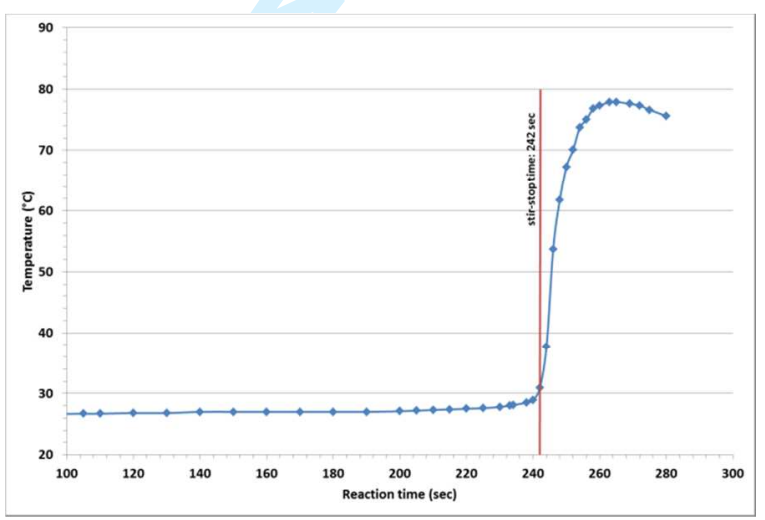

FIGURE 2 Temperature-time profile of a representative neat OctCA polymerization 
(initiator: Pyr dissolved in toluene, $[\mathrm{M}] /[\mathrm{I}]=8400$ )

\section{Set Time}

A generally accepted definition of set time is lacking. We developed a test for the determination of set times that mimics practical clinical requirements. The test consists of placing $1 \mathrm{~mL}$ OctCA in a $5 \mathrm{~mL}$ flat-bottom vial, injecting an appropriate amount of initiator by a microsyringe, manually vigorously agitating the system for 1-2 seconds, and immediately coating the liquid on a $\sim 2 \times 10 \mathrm{~cm}$ strip of fresh ventral porcine skin. After visually examining the coat, the surface of the coat is lightly touched with a latex-gloved index finger. Set time (in seconds) is recorded when the sensation felt touching the surface of the coating is similar to that touching the surface of a Postlt Self-stick removable paper. This test gives reproducible time readings even when practiced by less experienced operators.

Experiments were carried out to determine monomer conversions at stir-stop and set times. Thus, to $1 \mathrm{~g}$ OctCA stirred in a $5 \mathrm{~mL}$ flatbottom vial containing a small stir bar was injected a desired quantity of DMT initiator and the system was stirred. During the induction period a small drop ( $\sim 0.05 \mathrm{~g}$ ) of the liquid was removed from the charge by a Pasteur pipet and placed on top of the probe in the Teflon ring of the FTIR instrument. A FTIR spectrum was obtained and the absorption at $3124 \mathrm{~cm}^{-1}$ associated with $=\mathrm{CH}_{2}$ stretch was analyzed (Spectrum A, Figure 3). Stirring was continued and a second spectrum was acquired at stirstop time (Spectrum B, Figure 3). The lag between stir-stop time and acquiring the spectrum was $\sim 5$ seconds. According to the spectrum (and taking the sensitivity of the instrument into consideration), monomer conversion at stir-stop time was $\geq 90 \%$. Subsequently, the surface of the product in the FTIR instrument was probed by lightly touching it with the tip of a needle to ascertain that the gooey mass changed to a hard solid, i.e., set has occurred.

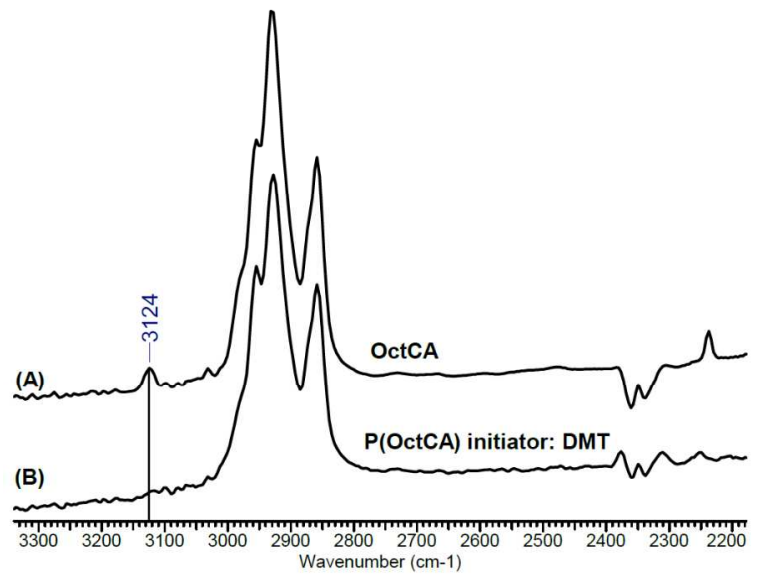

FIGURE 3 FTIR spectra of a representative charge during the induction period $(\mathbf{A})$, and at stir-stop time (B).

\section{RESULTS AND DISCUSSION}

\section{OctCA Polymerizations with N,N-Dimethyl Toluidine (DMT)}

The scientific and patent literatures were searched to identify highly reactive anionic initiators for alkyl-CA polymerization in general and OctCA in particular. Among the many kinds of initiators (e.g., amines, pyridines, phosphines, alkonium salts, etc.) initially we employed DMT because of its demonstrated reactivity and initiating efficiency, ease of handling, miscibility with CAs, and low price. ${ }^{4-8}$ Subsequent research substantiated expectations in respect to DMT, and our earlier homo- and copolymerization research was carried out with this initiator (see the previous paper in this series). In view of the considerable experience gained with DMT, this base became our "control" searching for more reactive initiators.

There is agreement in the literature in regard to the mechanism of initiation of CA polymerization induced by DMT. According to numerous investigators ${ }^{9-11}$ DMT initiates the polymerization of CAs by Michael addition to the monomer, followed by anionic chain growth (addition) polymerization by the zwitterion: 


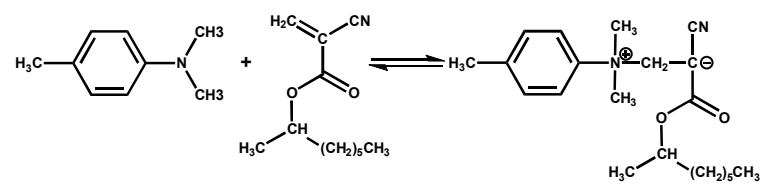

Support for this mechanism was the finding that poly(4-vinylpyridine) initiates the graft polymerization of Et-CA. ${ }^{11}$ Further, NMR and UV spectroscopic investigations also substantiated initiation by zwitterions. $^{11-13}$ Pepper and coworkers discussed the mechanism and kinetics of Et- and Bu-CA polymerizations initiated by various tertiary amines, and speculated about the nature of the zwitterion initiating species, and active chain ends (free ions, tight ion pairs) involved in these polymerizations. $^{1,11-15}$

An obvious consequence of zwitterion initiation with DMT is that the polycyanoacrylates formed should contain an aromatic head group. In the course of these investigations we analyzed by ${ }^{1} \mathrm{H}$ NMR and MALDI-TOF spectroscopies the structures of $\mathrm{P}(\mathrm{OctCA}) \mathrm{s}$ obtained under various conditions with DMT, however, failed unambiguously to identify the end groups.

\section{${ }^{1} \mathrm{H}$ NMR and MALDI-TOF Analysis}

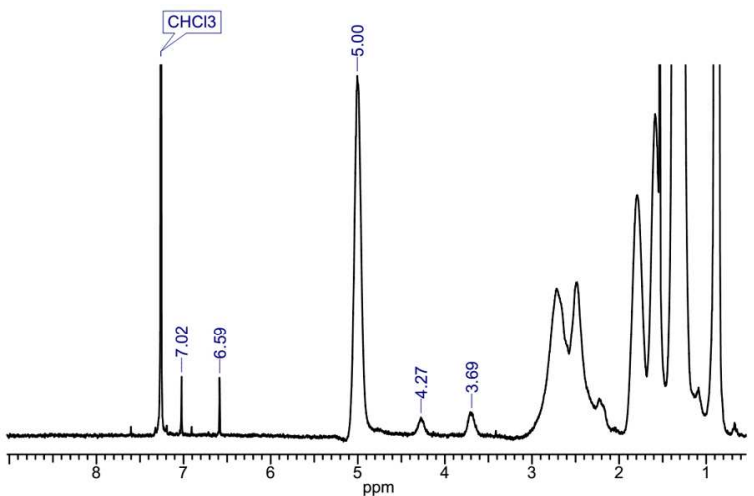

FIGURE $4{ }^{1} \mathrm{H}$ NMR spectrum of a representative poly $\left(\right.$ OctCA) (prepared with DMT $[\mathrm{M}]_{0} /[\mathrm{I}]_{0}=60$ )

Efforts were made to elucidate the mechanism of initiation of OctCA polymerization induced by DMT. If initiation of CA polymerization by $N$ bases occurs via zwitterions (see above), the polymerization of OctCA by DMT should produce the $\mathrm{CH}_{3}-p \mathrm{C}_{6} \mathrm{H}_{4}-\mathrm{N}^{+}\left(\mathrm{CH}_{3}\right)_{2}$ - head group , readily discernible by ${ }^{1} \mathrm{H}$ NMR and MALDI-TOF analysis. To facilitate spectroscopic analysis, we prepared $\mathrm{P}($ OctCA)s using relatively low DMT concentrations (e.g., $[\mathrm{M}] /[\mathrm{I}]=10 / 1$ ) to reduce the molecular weight of the polymer. Surprisingly, neither high resolution ${ }^{1} \mathrm{H} N M R$ spectroscopy nor MALDI-TOF analysis indicated the presence of the expected aromatic head group.

Thus, Figure 4 , the ${ }^{1} \mathrm{H}$ NMR spectrum of a representative poly(OctCA), shows the absence of protons in the 7.0-8.5 ppm (i.e., protons on the heteroaromatic ring) range. The singlets at 6.59 and $7.02 \mathrm{ppm}$ due to olefinic protons of OctCA indicate the presence of small amounts of unreacted monomer. The resonances at 4.27 and $5.00 \mathrm{ppm}$ are due to the protons of 1-octyl $\left(-\mathrm{OCH}_{2}\left(\mathrm{CH}_{2}\right)_{6} \mathrm{CH}_{3}\right)$ and 2-octyl ($\left.\mathrm{OCH}\left(\mathrm{CH}_{3}\right)\left(\mathrm{CH}_{2}\right)_{5} \mathrm{CH}_{3}\right)$ groups, respectively. The resonance at $3.69 \mathrm{ppm}$ suggests the presence of $\mathrm{HO}-\mathrm{CH}_{2}$ - groups.

Further, Figure 5 shows the MALDI-TOF spectrum of $\mathrm{P}$ (OctCA) acquired under standard conditions (linear mode). Assuming singly charged potassiated ions i.e., [polymer $+\mathrm{K}]^{+}$, the resolved sharp peaks (indicated with mass numbers) ranging from $3613(n=17)$ to $8481 \mathrm{Da}$ $(n>40)$ and beyond, are due to individual OctCA oligomers. The maximum peak intensity at $\mathrm{m} / \mathrm{z}$ $=4451$ corresponds to the 21-mer (calc. $=$ 4450.95). Figure 6 shows a more detailed view of the 21-mer and its satellites obtained in reflector mode. These data can be reconciled by assuming single potassiation leading to [polymer-K] ${ }^{+}$ions and initiation by $\mathrm{HO}^{-}$ions (adventitious moisture): 

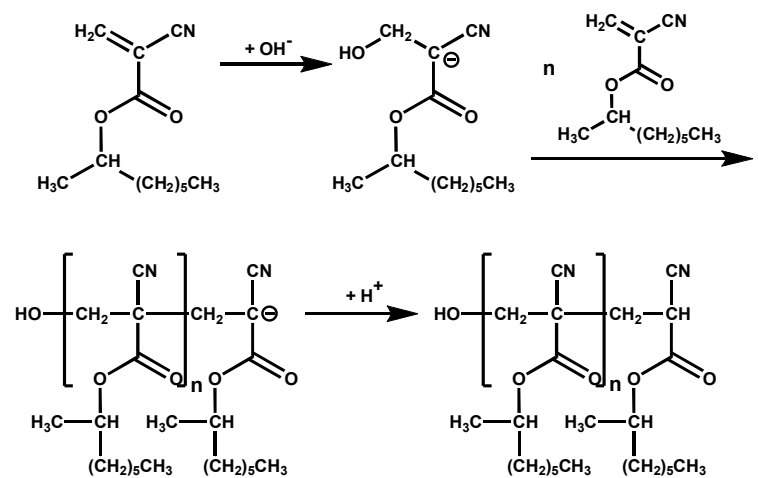

Mass spacing and absolute masses of the resolved oligomers provide additional structural information. Specifically, the mass spectrum indicates at least two other oligomer series having a mass spacing of 209.15 Da (the mass of OctCA), and differing by $\pm 30 \mathrm{Da}$ from the major component. The spectra do not show a single mass distribution of homologous reaction products and the nature of end groups is unclear.

Evidently, these ${ }^{1} \mathrm{H}$ NMR and MS analyses did not provide the expected evidence of initiation by zwitterions of OctCA polymerization. We are compelled to conclude that initiation of OctCA polymerization by DMT involves a series of unidentified complex steps, and the absence of aromatic head group indicates that the first step of propagation does not occur by zwitterions (see above). Some of the findings may be interpreted to suggest initiation by $\mathrm{HO}^{-}$ (i.e., traces of moisture).

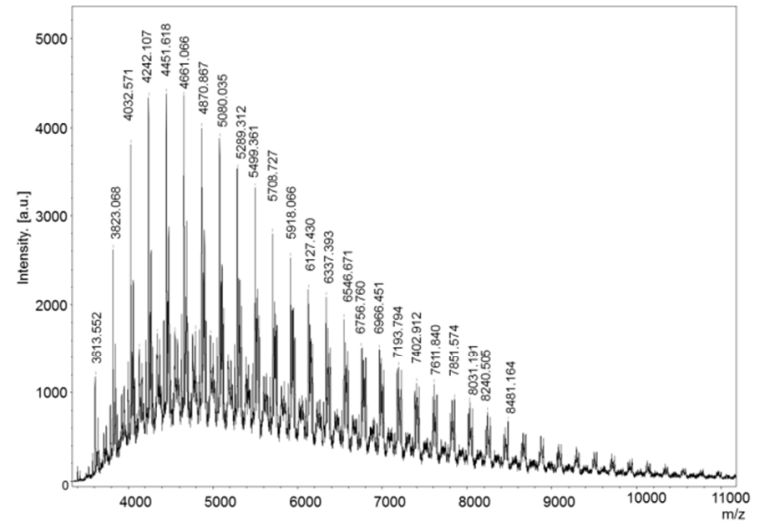

FIGURE 5 MALDI-TOF Spectrum of Poly(OctCA) Prepared Under Standard Conditions (linear mode).

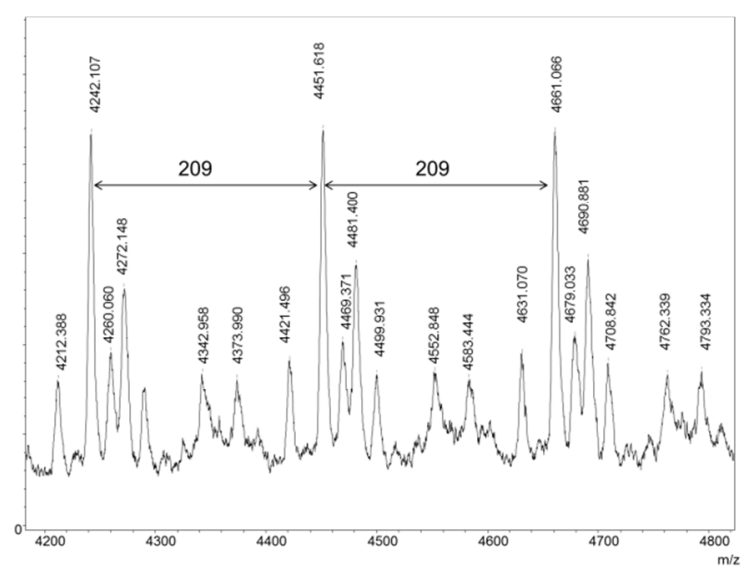

FIGURE 6 Part of the Mass Spectrum of $\mathrm{P}$ (OctCA). Besides the expected mass of 4451 Da two additional signals appear with a mass difference of $\pm 30 \mathrm{Da}$ (= $\mathrm{HCHO}$ ) (reflector mode).

\section{Polymerization with various initiators}

In addition to DMT, we investigated $\mathrm{Pyr}, \mathrm{Et}_{3} \mathrm{~N}$, $A B C O$, and $D A B C O$ as initiators for neat OctCA polymerization:

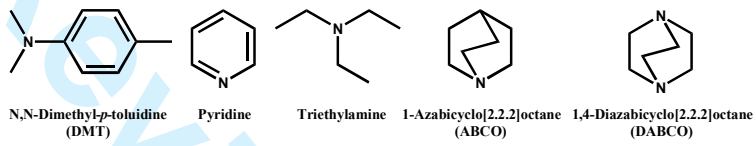

Except for $\mathrm{ABCO}$, these molecules, have been used by earlier investigators and were found highly reactive inducing the polymerization of alkyl CAs. Among the tertiary aliphatic amines ABCO appeared particularly promising because of its high nucleophilicty and unencumbered $\mathrm{N}$ atom. We thought, erroneously as it turned out (see below), that $A B C O$ will be more reactive than $\mathrm{Et}_{3} \mathrm{~N}$ because the three $\mathrm{Et}$ groups in the latter may sterically hinder the approach of the monomer during initiation. According to $a b$ initio calculations steric hindrance severely retards polymerization of Et-CA (16). In contrast to $\mathrm{Et}_{3} \mathrm{~N}$, such steric hindrance would be absent with $\mathrm{ABCO}$ because the three $-\mathrm{CH}_{2}-\mathrm{CH}_{2}$ - groups on the $\mathrm{N}$ atom are forced out-of-the-way 
rendering the $\mathrm{N}$ 's electron pair unencumbered for initiation.

DABCO with two unencumbered $\mathrm{N}$ atoms was selected for similar reasons, and because of its low price. DABCO was used by a previous team to initiate the polymerization of various alkyl $\mathrm{CAs}^{16}$; however, these workers used aqueous buffers as reaction media, which obscures their results since water is an initiator of CA polymerization. $^{3}$

Since $A B C O$ and $D A B C O$ are crystalline, they had to be dissolved in an inert solvent (i.e., toluene or THF) for using them as initiators. Dissolving and using these solids in toluene or THF lead to valuable observations in regard to solvent polarity effects (see below).

We were also interested examining the initiating reactivity of pyridine, as pyridine and its derivatives were found to induce CA polymerizations. ${ }^{2,14,15}$ However, we could not carry out neat OctCA polymerizations with pyridine because of the very high reactivity of this base. The moment a smallest drop of pyridine was added to OctCA, a solid blob of polymer formed around the drop, and homogeneous mixing became impossible. Thus, pyridine had to be diluted with toluene or THF to generate data.

\section{Stir-Stop Time and Set Time}

While stir-stop time and set time are phenomenologically distinguishable (stoppage of stirring at stir-stop time, surface dryness at set time, see Experimental), their definition in polymer chemical terms is challenging. Repeated efforts have been made to determine monomer conversion, P(OctCA) molecular weights, and molecular weight distributions at stir-stop and set times at various $[\mathrm{M}]_{0} /[\mathrm{I}]_{0}$ ratios, however, the differences between these quantities were negligible (within experimental error). For instance, we found by FTIR spectroscopy that monomer conversions were $\geq 90 \%$ at stir-stop times, and that the spectra did not change upon reaching set time. Similarly, product molecular weights and distributions obtained at stir-stop and set times were indistinguishable.

The phenomenological difference between stirstop and set times may be due to the rate of heat dissipation after polymerization cessation. OctCA polymerization is extremely rapid and highly exothermic (see Figure 2) and the dissipation of the heat of polymerization to the surrounding medium takes time. At stir-stop time the temperature of the system is way above $\sim 53^{\circ} \mathrm{C}$, the $\mathrm{T}_{\mathrm{g}}$ of $\mathrm{P}(\operatorname{OctCA})$, and the products are hot gooey masses due to the accumulated heat of polymerization. After the heat is dissipated, the gooey mass cools to room temperature, and the product becomes hard and dry to the touch. Termination is likely due to protonation of the active growing ends by adventitious moisture. A small amount of chain growth may occur after stir-stop (i.e., after $\geq 90 \%$ conversion), however, this incremental growth is negligible and cannot be detected by GPC molecular weight determination.

Figure 7 summarizes stir-stop times obtained with various initiators. Contrary to convention but to better visualize the findings, we plotted [monomer]/[initiator] versus stir-stop time (instead of plotting, as customary, the dependent (stir-stop time) versus the independent ([monomer]/[initiator]) variable). Evidently, DMT is the least reactive initiator among those examined, as it requires relatively high initiator concentrations (low $[\mathrm{M}]_{0} /[\mathrm{I}]_{0}$ ratios) for polymerization. Increasing the polarity of the system, i.e., changing from neat monomer to a charge that also contains THF introduced with DMT, affects initiation efficiency relatively little. The inset in Figure 7 shows the effect of THF (i.e., 5 vol.\% DMT dissolved in THF), obscured by the larger dimensions of the main plot. In contrast to $D M T$, polymerizations induced by $A B C O$ and DABCO are quite sensitive even to slightly increasing the polarity of the system i.e., introducing THF with the initiator. 


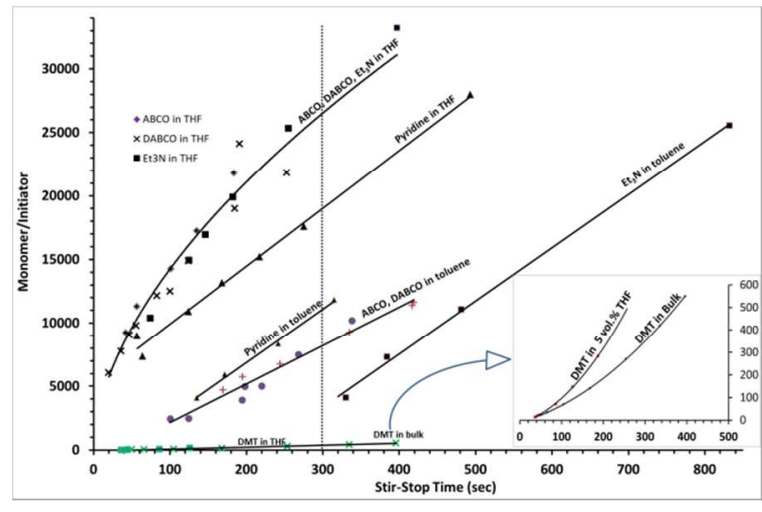

FIGURE 7 Relative Reactivities (Stir-Stop Times) of Various Initiators.

The fact that the straight lines in Figure 7 do not extrapolate to the origin is likely due to the presence of the $\sim 30 \mathrm{ppm} \mathrm{SO} \mathrm{S}_{2}$ in OctCA (i.e., the stabilizer added to ensure absence of polymerization during storage). Polymerizations are inhibited until a sufficient concentration of anionic species arises to start the reactions.

The data obtained with $A B C O$ and $D A B C O$ are of interest because: (a) the initiating reactivities of these tertiary cyclic aliphatic amines dissolved in toluene and even more so in THF, are far superior to that of DMT, (b) their reactivities are very similar (within experimental error) both in toluene and in THF, and (c) their reactivities are far higher when dissolved in THF than in toluene.

The intersections of the experimental plots with the vertical dotted line at $300 \mathrm{sec}$ provide a means of comparison of the relative reactivities of the initiating systems. By this measure the order of initiating reactivities in the presence of THF is: DMT $\ll$ Pyr $<\mathrm{Et}_{3} \mathrm{~N} \sim \mathrm{ABCO} \sim \mathrm{DABCO}$, while in the presence of toluene this order is DMT $<\mathrm{Et}_{3} \mathrm{~N}<\mathrm{ABCO} \sim \mathrm{DABCO}<$ Pyr. Evidently, even a very small amount of polar solvent used to dilute the initiator strongly affects relative initiator reactivities.

Structural considerations explain these observations: (a) the nucleophilicty of the aliphatic cyclic amines, $A B C O$ and $D A B C O$, is higher than that of $D M T$ due to the electron releasing effect of the aliphatic groups (i.e., the aliphatic substituents in $A B C O$ and $D A B C O$ are more electron releasing than the aromatic group in DMT); (b) only one of the two $\mathrm{N}$ atoms in $D A B C O$ is probably active, rendering $A B C O$ and $D A B C O$ similar in reactivity. The likely reason is that after one of DABCO's $\mathrm{N}$ atoms donates its electron pair and becomes positively charged, the zwitterion is reluctant to donate its second N's electron pair since this would create an energetically unfavorable second positive site in the molecule.

\section{CONCLUSIONS}

Methodologies were developed to measure initiator reactivity for neat OctCA polymerizations induced by select $\mathrm{N}$ bases. Polymerizations are very rapid and exothermic upon contact with $\mathrm{Et}_{3} \mathrm{~N}, \mathrm{ABCO}$ and $\mathrm{DABCO}$, and Pyr, and much slower with DMT initiator. Overall rates are faster with initiators dissolved in THF than in toluene indicating polarity effects. Relative initiator reactivity is discussed in terms of structural parameters. According to ${ }^{1} \mathrm{H} \quad \mathrm{NMR}$ and MMALDI-TOF spectroscopy $\mathrm{P}$ (OctCA)s obtained by the use of DMT did not incorporate the expected DMT head group, which suggests complex initiation. Evidence for initiation by adventitious moisture is presented and discussed. It is of practical significance that the set time of OctCA polymerization can be precisely controlled in the 60-120 seconds range by the use of appropriate concentration of select initiators. Finally, let it be emphasized that the polymerization of OctCA, i.e., the formation of $\mathrm{P}$ (OctCA) wound closure coats, is not "curing", as it is often incorrectly referred to, as the coat is not crosslinked (not a network), but a soluble stiff thermoplastic.

\section{ACKNOWLEDGEMENTS}

We wish to acknowledge lan McCullough's professional help searching the patent and scientific literature, and Chris Wesdemiotis for acquiring and interpreting MALDI-TOF spectra.

\section{REFERENCES AND NOTES}


1. E.F. Donnely, D.S. Johnston, D. C. Pepper, D.J. Dunn, J. Polym. Sci. Pol. Lett. 1977, 15, 399-405.

2. J.P. Cronin, D. C. Pepper, Makromol. Chem. 1988, 189, 85-102

3. I.C. Eromosele, D.C. Pepper, B. Ryan, Macromol. Chem. 1989, 190, 1613-1622.

4. C.J. Buck, (Johnson \& Johnson), U.S. Patent. 3,903,055, Sept 2, 1975

5. J.P. Kennedy, Y. Kwon, S. Jewrajka U.S. Patent. 2010/0144996, Jun 10, 2010

6. Y. Kwon, J. P. Kennedy, Polym. Advan. Technol. 2007, 18, 800-807.

7. Y. Kwon, J. P. Kennedy, Polym. Advan. Technol. 2007, 18, 808-813.

8. K. N. Broadley, J. Guthrie, N. Swords U. S. Patent. 2010/0035997, Feb 11, 2010
9. M. G. Han, S. Kim, S. X. Liu, Polym. Degrad. Stab. 2008, 93, 1243-1251.

10. D.S. Johnston, D.C. Pepper, Makronol Chem. 1981, 182, 407-420.

11. D.S. Johnston, D.C. Pepper, Makromol. Chem. 1981, 182, 393-406.

12. D.S. Johnston, D.C. Pepper, Makromol. Chem. 1981, 182, 421-435.

13. D.C. Pepper, Polym. J. 1980, 12, 629-637.

14. D. C. Pepper, R. Bernard, Makronolekul. Chem. 1983, 184, 395-410.

15. C. Lochen, N. Otte, Macromolecules 2010, 43, 9674-9681.

16. D. Katti, N. Krishnamurti, J. Appl. Polym. Sci. 1999, 74, 336-344. 


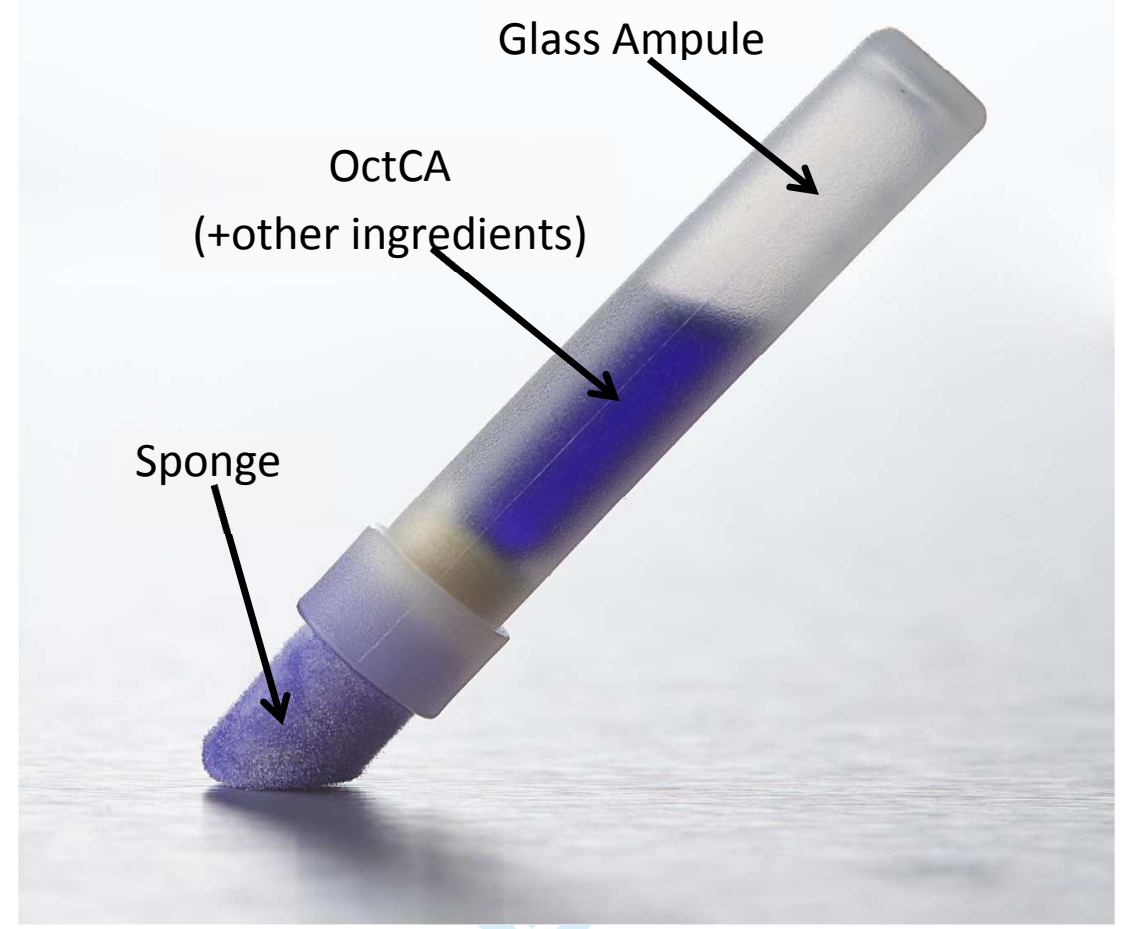

FIGURE 1 A typical delivery device for cyanoacrylate wound closure adhesives. The active ingredients (plus various additives, i.e., stabilizer, viscosifying agent, dye, etc.) are in a thin walled glass ampule, which, when broken, sends the liquid through the sponge onto the skin. 
10

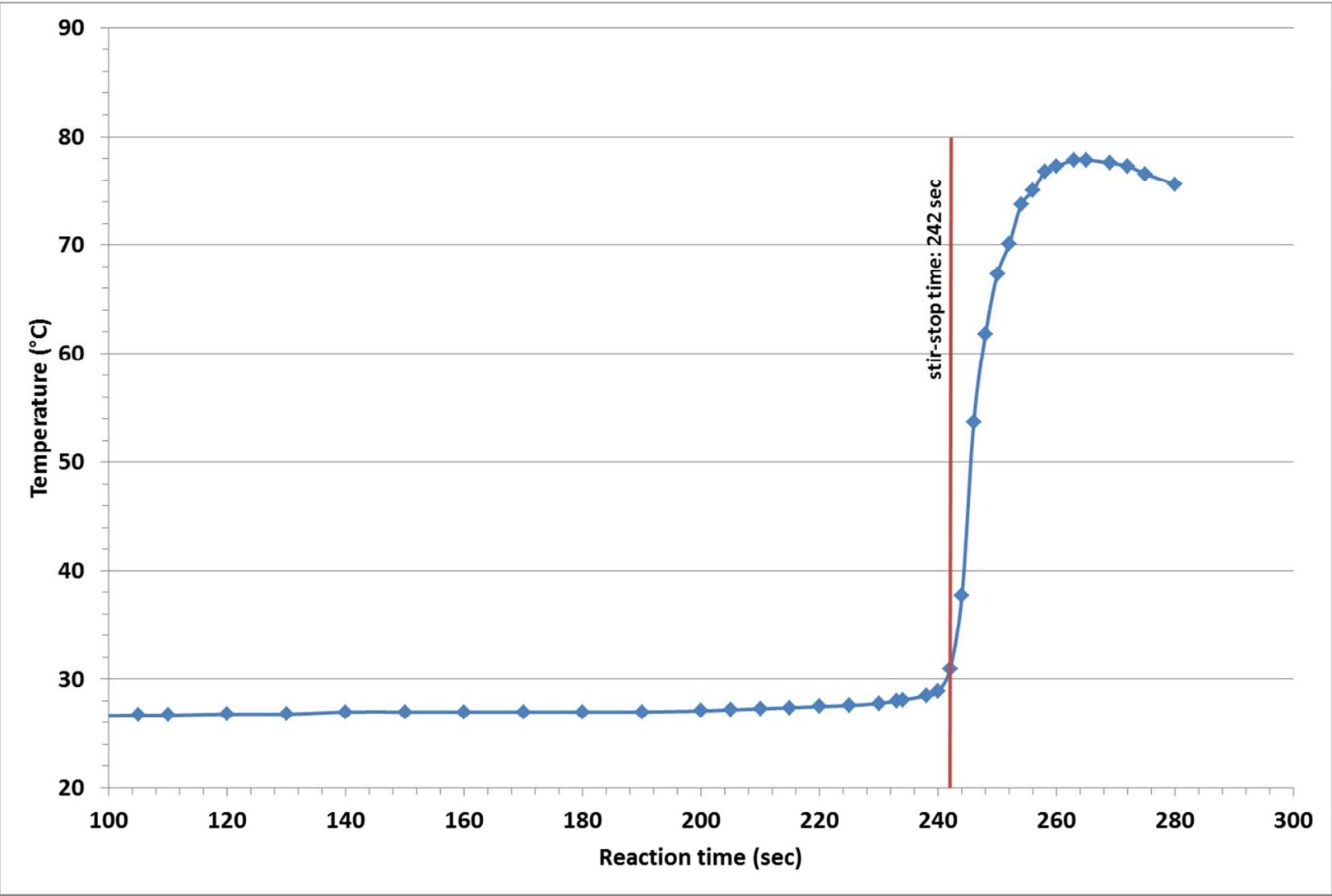

FIGURE 2 Temperature-time profile of a representative neat OctCA polymerization (initiator: Pyr dissolved in toluene, $[\mathrm{M}] /[\mathrm{I}]=8400$ ) 


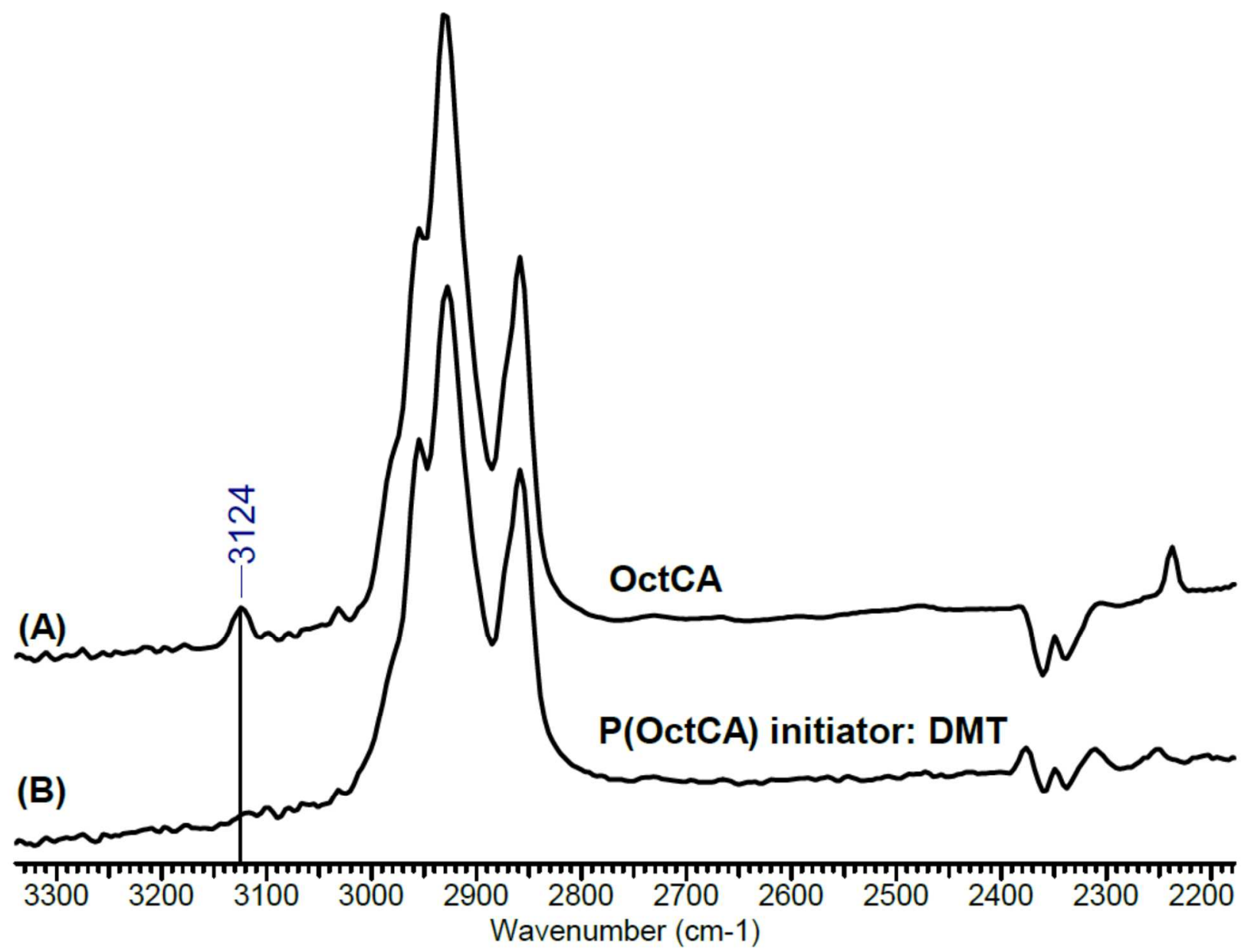

FIGURE 3 FTIR spectra of a representative charge during the induction period (A), and at stir-stop time (B). 
<smiles>C=C=C=C(CCCC)[C@H](C)OC(=O)C(=C)C#N</smiles> 


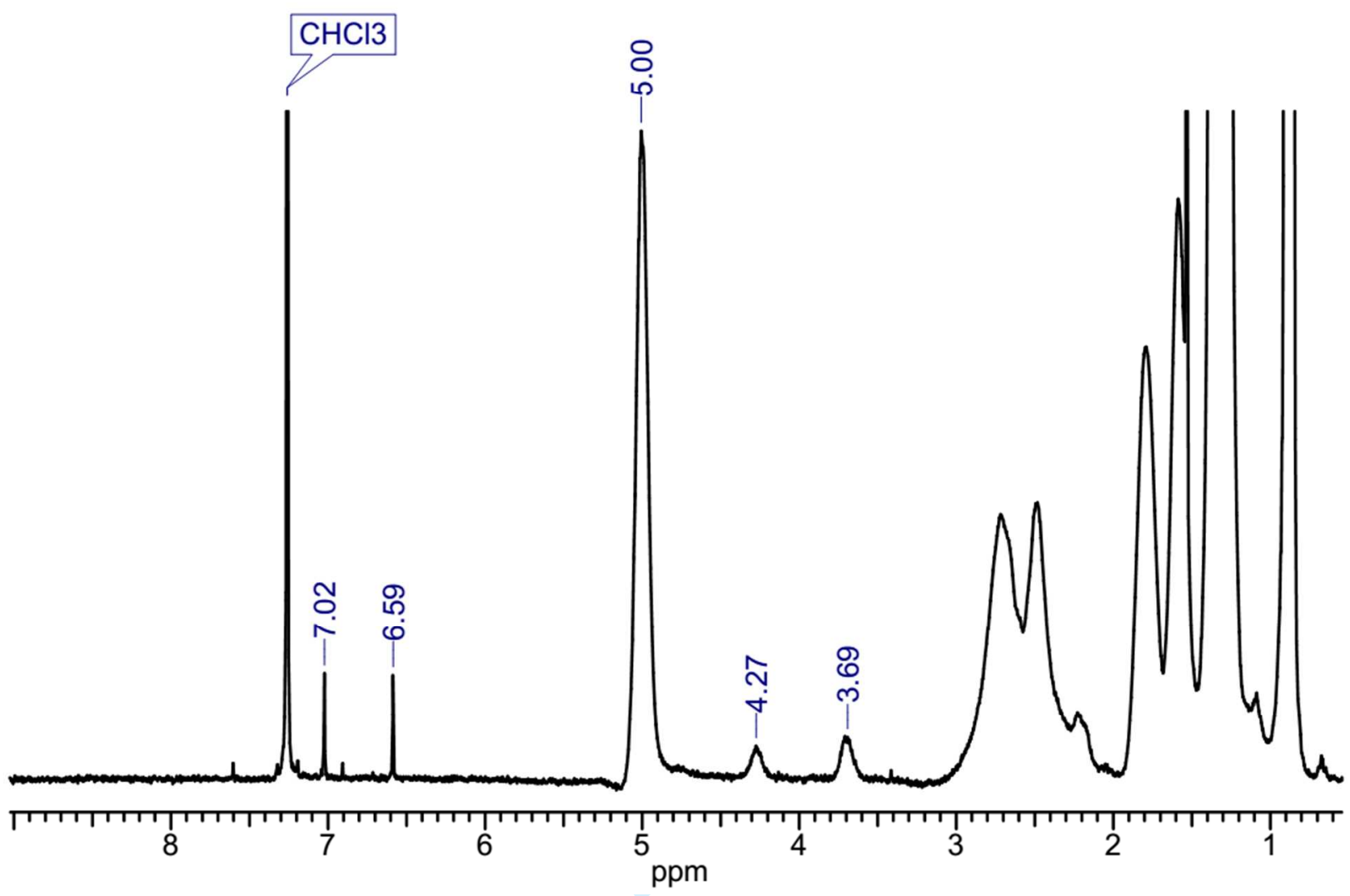

FIGURE $4{ }^{1} \mathrm{H}$ NMR spectrum of a representative poly(OctCA) (prepared with DMT $[\mathrm{M}]_{0} /[]_{0}=60$ ) 


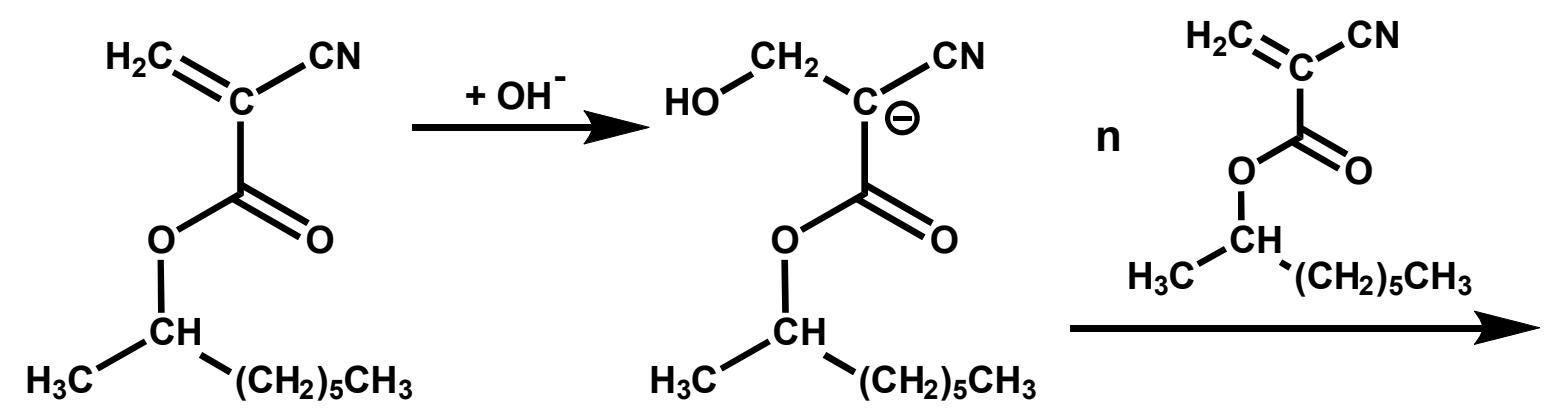<smiles>CCCCCCCC(C)OC(=O)C(C#N)(CC(C)(O)CC)C(C#N)(CC(C)(C)CCCC)C(=O)OC(C)C</smiles><smiles>CCCCCC(C)CC(C)(O)CC(C)(CC(C#N)C(=O)OC(C)CCCCC)C(=O)OC(C)C</smiles> 


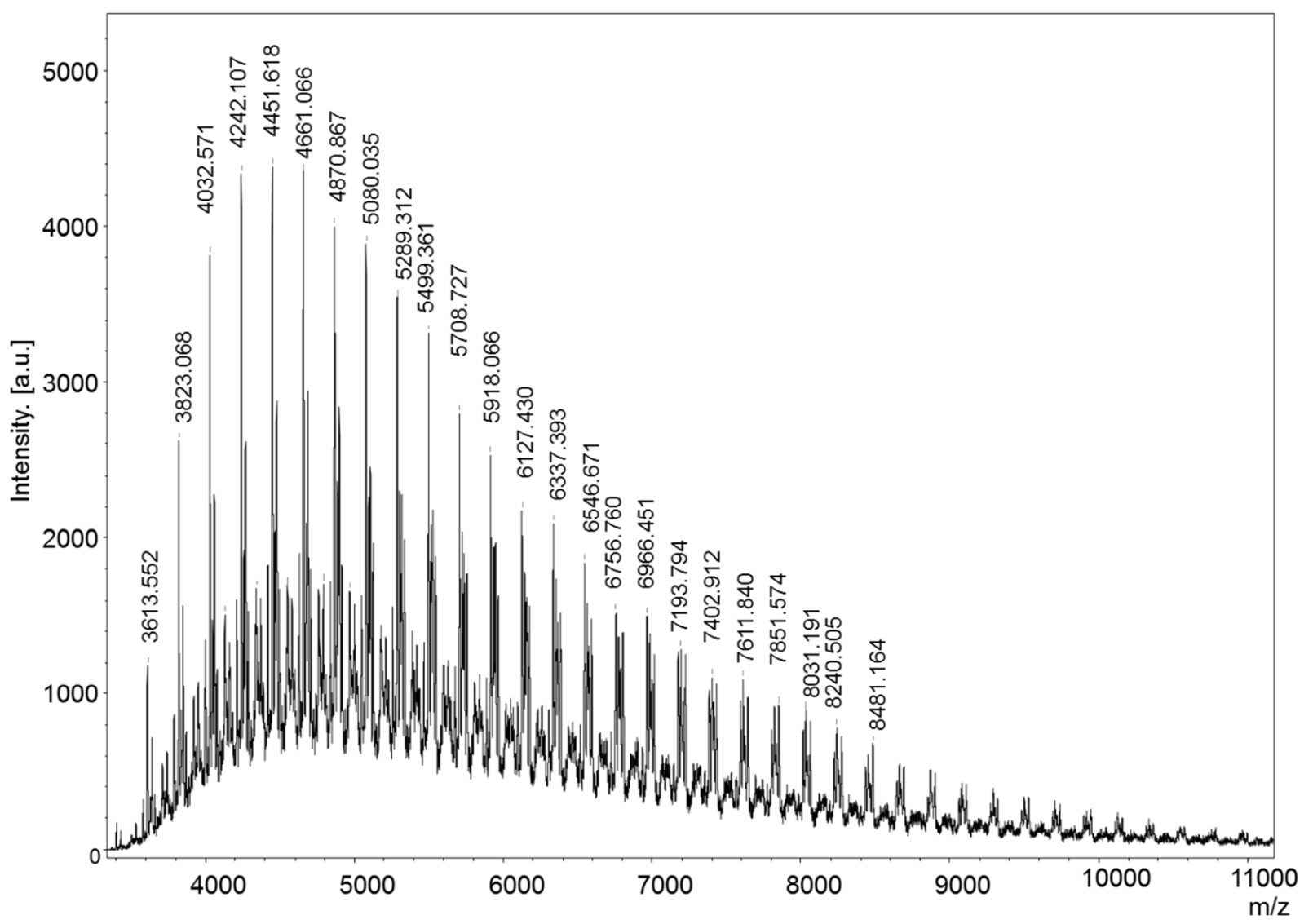

FIGURE 5 MALDI-TOF Spectrum of Poly(OctCA) Prepared Under Standard Conditions (linear mode). 


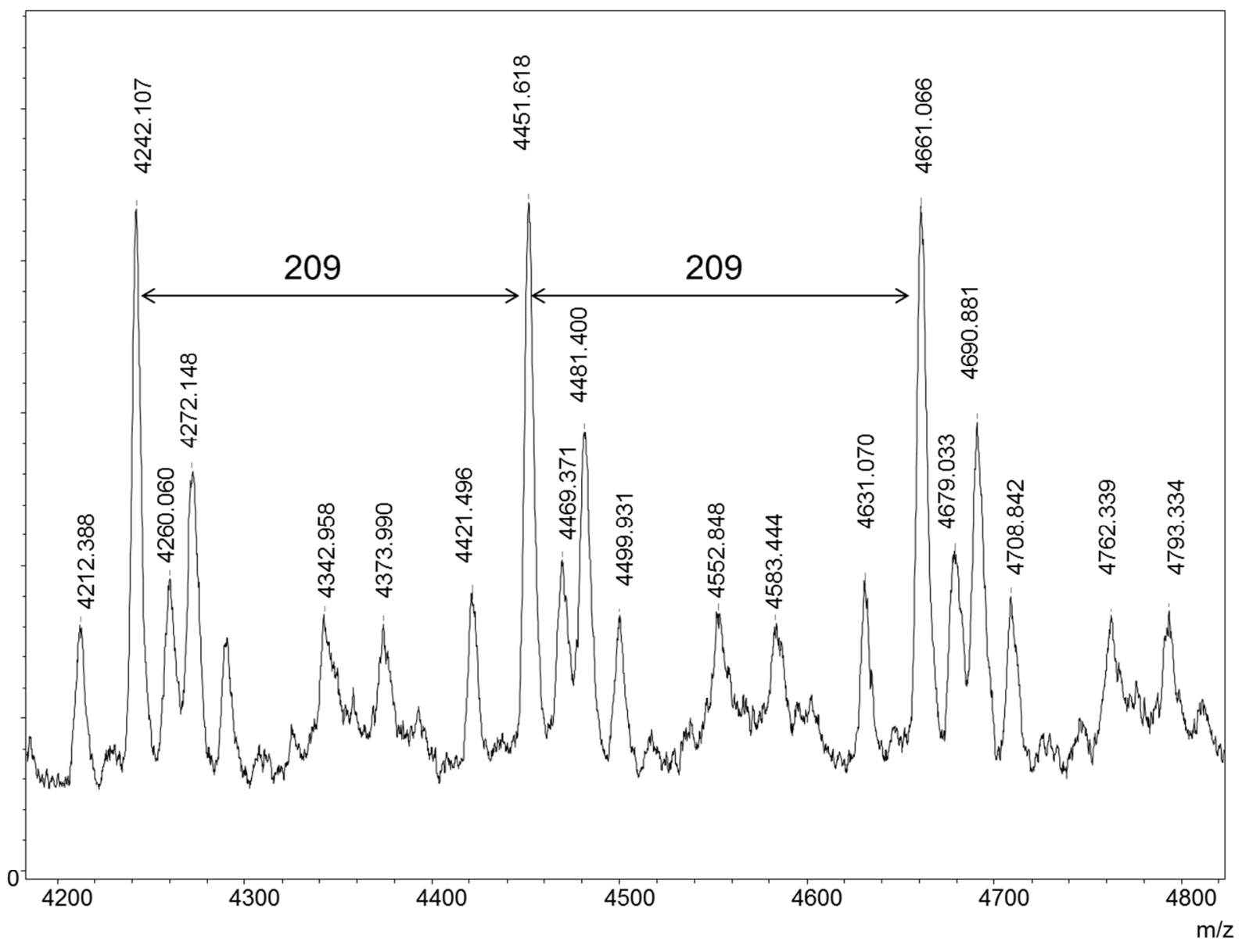

FIGURE 6 Part of the Mass Spectrum of P(OctCA). Besides the expected mass of 4451 Da two additional signals appear with a mass difference of $\pm 30 \mathrm{Da}$ (= $\mathrm{HCHO}$ ) (reflector mode). 
<smiles>Cc1ccc(N(C)C)cc1</smiles>

N,N-Dimethyl-p-toluidine (DMT)

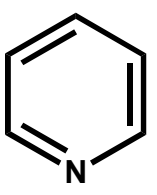

Pyridine<smiles>CCN(CC)CC</smiles>

Triethylamine
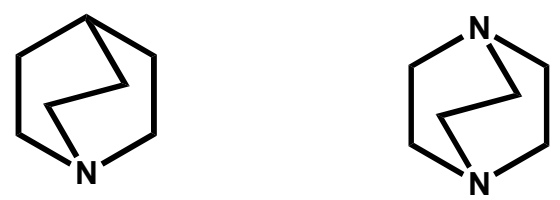
(ABCO) zabicyclo[2.2.2]octane (DABCO) 


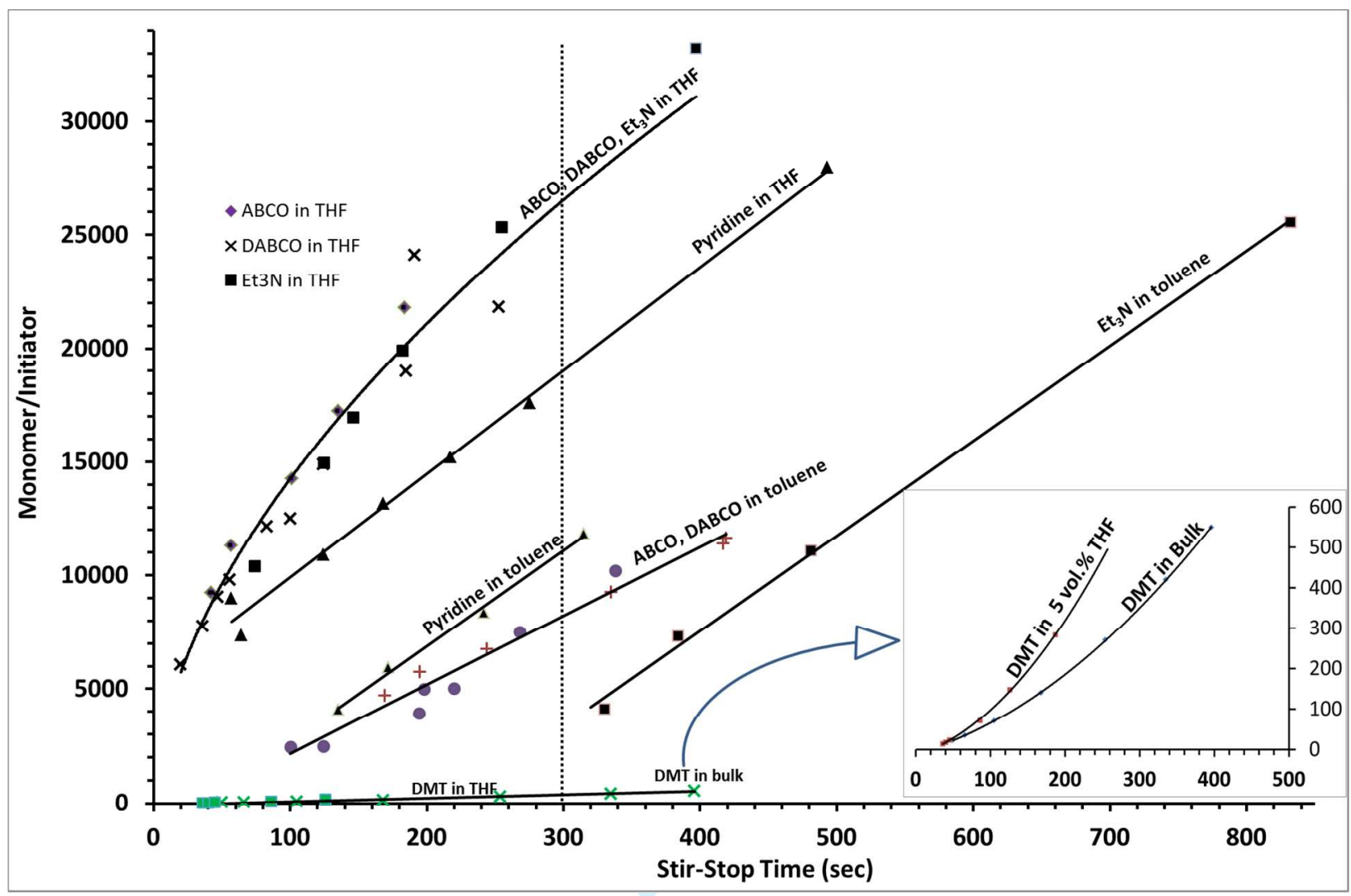

FIGURE 7 Relative Reactivities (Stir-Stop Times) of Various Initiators. 